\title{
Rooming-in for Infants at Risk for Neonatal Abstinence Syndrome: Outcomes 5 Years following Its Introduction as the Standard of Care at One Hospital
}

\author{
Adam Isaiah Newman, MD ${ }^{1,2(0)}$ Dane Mauer-Vakil, BSc ${ }^{3}$ Helen Coo, MSc ${ }^{2}$ Lynn Newton, NNP1,2,4,5 \\ Emily Wilkerson, BMus ${ }^{5}$ Sarah McKnight, MD ${ }^{2}$ Susan B. Brogly, PhD ${ }^{6}$ \\ ${ }^{1}$ Department of Family Medicine, Queen's University, Kingston, \\ Ontario, Canada \\ 2 Department of Pediatrics, Queen's University, Kingston, Ontario, \\ Address for correspondence Adam Isaiah Newman, MD, Kingston \\ Health Sciences Centre (Kingston General site), 76 Stuart Street, \\ Kingston, ON K7L 2V7, Canada \\ Canada \\ (e-mail: dr.adam.newman@gmail.com).
}

${ }^{3}$ Health Services Research Program, Dalla Lana School of Public

Health, University of Toronto, Toronto, Ontario, Canada

${ }^{4}$ Women's and Children's Program, Kingston Health Sciences Centre, Kingston, Ontario, Canada

${ }^{5}$ School of Medicine, Queen's University, Kingston, Ontario, Canada

${ }^{6}$ Department of Surgery, Queen's University, Kingston, Ontario,

Canada

Am J Perinatol 2022;39:897-903.

\section{Abstract}

Keywords

- neonatal abstinence syndrome

- opioid use disorder

- nonpharmacological treatment

- opioid-dependent infants
Objective The practice of rooming-in for opioid-dependent infants was introduced as the standard of care at our hospital following a pilot study which demonstrated that such infants had shorter lengths of stay and were less likely to require pharmacological treatment. We sought to determine whether these benefits have continued, and whether outcomes support continuing to use rooming-in as standard care.

Study Design Opioid-dependent infants delivered at 36 weeks gestation or later between January 1, 2015, and December 31, 2019, were eligible for rooming-in. Charts were reviewed and data were extracted regarding maternal and infant conditions, whether neonatal pharmacological treatment was required, and total length of hospital stay. Outcomes were compared with two historical groups reported in a previous pilot study: 24 healthy near-term opioid-dependent newborns who were admitted directly to the neonatal intensive care unit (NICU) prior to the introduction of rooming-in (May 1, 2012-May 31, 2013), and 20 similar opioid-dependent infants who were the first to room-in at our hospital (September 1, 2013-September 30, 2014). Results Only $3.5 \%$ of 57 infants who roomed-in during the 5 -year study period required pharmacological treatment, compared with $15 \%$ who roomed-in during the first year of the program's introduction and $83.3 \%$ who had been admitted directly to the NICU. The median length of stay remained 5 days for infants rooming-in, compared with 24 days for opioid-dependent infants in the cohort admitted to the NICU. received

June 3,2020

accepted after revision

September 24, 2020

published online

November 17, 2020
DOI https://doi.org/

10.1055/s-0040-1719182.

ISSN 0735-1631. (c) 2020. The Author(s).

This is an open access article published by Thieme under the terms of the Creative Commons Attribution-NonDerivative-NonCommercial-License, permitting copying and reproduction so long as the original work is given appropriate credit. Contents may not be used for commercial purposes, or adapted, remixed, transformed or built upon. (https://creativecommons.org/ licenses/by-nc-nd/4.0/)

Thieme Medical Publishers, Inc., 333 Seventh Avenue, 18th Floor, New York, NY 10001, USA 
Conclusion Early observations of the benefits of rooming-in on neonatal outcomes were sustained. Infants allowed to room-in were significantly less likely to require initiation of pharmacotherapy and a prolonged hospital stay than similar infants prior to the implementation of rooming-in as standard care. A large proportion of the infants who might have benefited from rooming-in required admission to the NICU for reasons other than neonatal abstinence syndrome (NAS).

\section{Key Points}

- Benefits of rooming-in for near-term opioid-dependent infants were sustained or increased.

- Rooming-in is sustainable as standard care for these newborns.

- Many infants required admission to NICU for reasons other than NAS.

The opioid crisis is a serious public health issue throughout North America. Between January 2016 and September 2019, there were more than 14,700 opioid-related deaths in Canada. ${ }^{1}$ The age-standardized years-of-life lost from 1990 to 2014 due to opioid-related deaths have increased by $142.2 \%{ }^{2}$ The negative impact of this crisis has extended to pregnant women and their offspring, as is evidenced by ongoing increases in rates of neonatal abstinence syndrome (NAS). Dawson et al reported a sixfold increase in NAS incidence in Ontario from 0.99 per 1,000 live births in 2003 to 5.94 in 2016 . $^{3}$ During a similar period in the United States, a fivefold increase from 1.5 to 8.0 per 1,000 hospital births was observed. ${ }^{4}$

NAS refers to a group of signs that occur when an infant exposed in utero to drugs such as opioids, benzodiazepines or nicotine, experiences withdrawal in the hours or days after birth. ${ }^{5}$ Withdrawal caused specifically by antenatal exposure to opioids (e.g., oxycodone, heroin, fentanyl, or methadone among others) is manifested by signs of dysregulation in the gastrointestinal and central and autonomic nervous systems. ${ }^{6}$ Infants affected by NAS have a greater probability of long-term psychosocial complications, including behavioral issues, ${ }^{7}$ poor academic performance, ${ }^{8}$ and neurodevelopmental deficiencies. ${ }^{9}$ Until recently, standard care of opioid-exposed newborns included admission to a neonatal intensive care unit (NICU) for monitoring, necessitating separation of the mother-infant dyad and frequently leading to pharmacotherapy for up to 21 days postbirth. ${ }^{10}$ NAS thus contributes to significant hospital costs, which increased from \$15.7 to \$26.9 million CAD in Canada between 2010 and $2014 .{ }^{11}$

Rooming-in-whereby a newborn remains with its mother postnatally-is the standard of care for mothers and infants unaffected by opioid dependence, but is considered an alternative care model for those affected by opioid use disorder (OUD) and dependence. According to the United Nations Children's Fund and the World Health Organization, ${ }^{12}$ rooming-in in the general population allows mothers to practice responsive feeding, which cannot be learned if the mother and infant are separated. Furthermore, the proximity afforded by rooming-in helps mothers recognize their infants' cues and better facilitates breastfeeding. ${ }^{12}$ Rooming-in is associated with benefits for mothers, including reduced postpartum depression, increased confidence in caring for the infant, and an improved experience of breastfeeding. ${ }^{13,14}$ Benefits for the infant include improved sleep quality, more stable body temperatures and blood sugar levels, and lower levels of stress hormones. ${ }^{13}$

There has been growing evidence to support the benefits of rooming-in for opioid-exposed newborns. A total of 12 studies have evaluated the utility of this intervention across the United States, Canada, and Europe, using retrospective and quality improvement study designs. ${ }^{15-26}$ Seven review articles published in 2018 and 2019 alone ${ }^{27-33}$ provide rich summaries of the subject. In a systematic mixed-study review analyzing both quantitative and qualitative data, MacVicar and Kelly found that optimizing nonpharmacological management of NAS (including consolation therapy and rooming-in) improved outcomes by lessening the need for pharmacotherapy and reducing hospital length of stay. ${ }^{30}$ Ryan et al concluded that management interventions including swaddling, breastfeeding, skin-to-skin contact, and environmental control (all of which are facilitated by roomingin) effectively manage NAS without the need to resort to pharmacotherapy. ${ }^{33}$ A recent systematic review and metaanalysis of care models in the United States, Europe, and Canada ( $n=549$ ) found that rooming-in (vs. NICU care) resulted in a reduction in the length of hospital stay by 10 days and in use of pharmacotherapy by $63 \% .{ }^{27}$ Wachman et al investigated both pharmacological and nonpharmacological interventions for NAS and confirmed these findings. ${ }^{29}$

In 2013, our hospital instituted a rooming-in program for opioid-exposed newborns, which was offered to any infant born at term to a mother consuming any of the following antenatally: opioid agonist therapy (OAT) for OUD; any regularly prescribed opioid medication for pain; or illicit opioids. ${ }^{19}$ A report published in 2016 by our group demonstrated that the program was associated with a reduction in the need for pharmacological treatment of NAS and a shorter hospital stay. ${ }^{21}$ Our objective in publishing the current data is to examine whether the positive impacts initially observed following the implementation of our program persisted over 
the subsequent 5 years during which rooming-in has been the standard care for otherwise healthy term opioid-exposed newborns in our hospital.

\section{Materials and Methods}

This study was reviewed for ethical compliance by the Queen's University Health Sciences and Affiliated Teaching Hospitals Research Ethics Board.

\section{Study Setting and Population}

The Kingston Health Sciences Centre (KHSC) is a tertiary care academic hospital in a medium-sized city in Ontario, Canada. A rooming-in program for opioid-exposed newborns was instituted at the Kingston General Hospital site of KHSC in June $2013,{ }^{21}$ the only site at which obstetrical and neonatal care occur in a city of $\sim 125,000$ people. ${ }^{34}$ KHSC is the referral center for a surrounding population of almost 600,000 and has the region's only Level 3 NICU. ${ }^{35}$ The process of implementing and evaluating the program was described in detail elsewhere. ${ }^{19}$ Briefly, eligible mothers and newborns are admitted after delivery to private rooms on the general pediatrics ward, rather than immediately transferring the infant alone to the NICU for observation as was standard practice prior to June 2013.

All pregnant women identified as being opioid dependent for any reason (defined as having consumed any opioid daily for at least 2 weeks prior to assessment, and having experienced withdrawal symptoms if an attempt was made to stop) and who were expecting to deliver at KHSC were referred to the rooming-in team. The team consists of a social worker, a neonatal nurse practitioner (L.N.), a family physician with expertise in perinatal addiction (A.I.N.), and a family and community support worker employed by Thrive. Thrive is a program started by the local Community Health Centre in 2012 in response to the opioid epidemic. The program offers practical support to pregnant women and mothers of children younger than 6 years, ${ }^{19,36}$ and a referral was offered to every eligible woman. Women diagnosed with OUD who were using illicit opioids at the time of referral were offered initiation of OAT. The team social worker maintained a list of all referrals, and each week the team met to review each prospective mother's readiness to room-in, and any possible social, psychological, or medical barriers.

Eligible women identified antenatally met with the team social worker at least once and were informed about the process of rooming-in and the need for near-constant presence on the ward with their infant after delivery. They were educated about nonpharmacological measures to soothe their infants' signs of NAS, including skin-to-skin contact, breastfeeding where possible, swaddling, the use of an oral soother (provided by the hospital), and taking advantage of the private room provided to minimize unnecessary noise and light. Breastfeeding was encouraged except when a mother chose not to or when a contraindication existed. The only contraindication occurring in our study sample involved a mother whose urine tested positive for metham- phetamine on toxicological testing at admission. Infants were ineligible for rooming-in for the following reasons: they were delivered at less than 36 weeks' gestational age; they met other standard medical criteria for NICU admission (e.g., any condition requiring cardiorespiratory resuscitation and/or support); or apprehension at birth was planned by Child and Family Services (CFS) for any reason. Otherwise, any opioid-dependent woman assessed antenatally who was planning on delivering at KHSC was offered rooming-in postnatally. As per hospital policy, signs of NAS were monitored and scored using a modified Finnegan scoring tool. ${ }^{37}$ Half-way through our study period, Grossman et al published a report describing their success with the Eat, Sleep, Console (ESC) method of assessment and management. ${ }^{22}$ The extent to which this innovation may have influenced the two clinicians who provided the majority of care for these rooming-in dyads (A.I.N. and L.N.) is addressed in the Discussion section.

Following Ontario clinical practice guidelines, morphine is used at our hospital as the first-line pharmacological treatment for NAS, and infants requiring initiation of morphine (three consecutive modified Finnegan scores $>8$; two consecutive scores $>12$ ) are transferred to the NICU for monitoring. ${ }^{38}$ Once stabilized, the infant is returned to room-in with its mother while being weaned from morphine. ${ }^{19}$ Mother-infant dyads who had been exposed antenatally to long-acting opioid agonists such as methadone or buprenorphine were kept in hospital for a minimum of 5 days; for mother/infant pairs exposed to any other opioid, the minimum stay was 72 hours.

For the current study, we included all eligible women who delivered one or more live born infants at KHSC between January 1, 2015, and December 31, 2019, inclusive ("20152019 cohort"). We did not include in our analysis any neonates requiring immediate admission to the NICU because of prematurity, CFS apprehension, medical comorbidity, or any combination thereof. Infants who were transferred to the NICU for any reason after having first initiated rooming-in were included in our analysis.

\section{Data Collection and Analysis}

Data were abstracted retrospectively by three of the authors (A.I.N., D.M.V., and E.W.), who reviewed the electronic medical record of each of the mothers and infants. Data included: demographics; maternal antenatal opioid and other drug use (both prescribed and illicit); cigarette smoking in pregnancy; whether the infant was apprehended at birth; comorbidities (maternal and infant); whether infants initially roomed-in with their mothers; whether infants required pharmacological treatment for NAS; type of feeding (breast milk, formula, or both); and length of stay. Cigarette smoking was based on the mothers' self-report, whereas the use of illicit recreational drugs and marijuana (cannabis was legalized for general use in Canada in October 2018) was scored as being present if the mother had one or more positive urine drug screens during her pregnancy. A small for gestational age variable was derived using the Fenton Canadian growth charts as $<10 \%$ for gestational age and sex. ${ }^{39}$ 
Two comparison groups were used in our study: (1) 24 opioid-dependent infants born in 2012 to 2013, prior to the implementation of the rooming-in program and (2) 20 opioiddependent infants born in 2013 to 2014, the pilot rooming-in program cohort. Both of these groups of infants were described in our prior study. ${ }^{21}$ Importantly, only infants who would have been eligible to room-in, had the program existed at the time, were included in this first comparison group (i.e., gestational age of at least 36 weeks; no apprehension at birth by CFS; no medical comorbidity requiring admission to the NICU). For the current study, outcomes were need for morphine, breastfeeding, and hospital length of stay. We compared these outcomes in the 2015 to 2019 cohort and the two comparison groups described above. We used the Pearson's chi-squared or Fisher's exact (morphine, breastfeeding) and Mann-Whitney's $U$ (length of stay) tests. Demographics, antenatal opioid and other drug use, and infant comorbidity that may have affected length of stay were also compared among the three groups using oneway analysis of variance (continuous variables) and Fisher's exact tests (categorical variables). All references to significance are based on an $\alpha$ of 0.05 (two-tailed tests where applicable).

\section{Results}

Over the 5-year study period, 84 women with opioid dependency had 98 pregnancies that resulted in obstetric deliveries of 100 infants. Forty-three infants required admission to the NICU and thus were excluded from our study. The characteristic of the remaining 57 mother-infant dyads are shown in -Table 1, together with those of the two reference

Table 1 Characteristics of three groups of mother-infant opioid-exposed dyads born in a tertiary care teaching hospital in Kingston, Ontario (1) prior to implementation of a rooming-in program (2012-2013), (2) in the 13-month period shortly following implementation of a rooming-in program (2013-2014), and (3) from 2015 to 2019

\begin{tabular}{|c|c|c|c|c|}
\hline & $\begin{array}{l}2015-2019 \\
\text { rooming-in } \\
\text { group }^{\mathrm{a}}(n=57)\end{array}$ & $\begin{array}{l}2013-2014 \\
\text { rooming-in } \\
\text { group }^{b, c}(n=20)\end{array}$ & $\begin{array}{l}2012-2013 \\
\text { nonrooming-in } \\
\text { group }^{b, d}(n=24)\end{array}$ & $p$-Value \\
\hline Maternal age at delivery, y & $30.1(5.5)$ & $31.1(5.8)$ & $29.7(3.4)$ & 0.62 \\
\hline Primiparous & $19(33)$ & $7(35)$ & $5(21)$ & 0.52 \\
\hline Previous children with NAS & $19(50)$ & $3(25)$ & $3(19)$ & 0.06 \\
\hline \multicolumn{5}{|l|}{ Prenatal opioid exposure } \\
\hline Methadone & $36(63)$ & $12(60)$ & $15(62)$ & \multirow[t]{3}{*}{0.15} \\
\hline Buprenorphine & $10(18)$ & 0 & $2(8.3)$ & \\
\hline Other $^{f}$ & $11(19)$ & $8(40)$ & $7(29)$ & \\
\hline \multicolumn{5}{|l|}{ Other antenatal exposures } \\
\hline Cigarettes & $42(74)$ & $12(60)$ & $16(67)$ & 0.49 \\
\hline Marijuana & $16(28)$ & $3(15)$ & $2(8.3)$ & 0.11 \\
\hline SSRIs & $9(16)$ & $3(15)$ & $1(4.2)$ & 0.40 \\
\hline Benzodiazepines & $5(8.8)$ & $1(5.0)$ & $1(4.2)$ & 0.87 \\
\hline Female & $26(46)$ & $9(45)$ & $14(58)$ & 0.57 \\
\hline Gestational age, wk & $39.3(1.2)$ & $39.5(1.4)$ & $39.6(1.5)$ & 0.53 \\
\hline Birth weight, $g$ & $3,283(450)$ & $3,262(366)$ & $3,314(532)$ & 0.93 \\
\hline Small for gestational age & $6(11)$ & $2(10)$ & $4(17)$ & 0.70 \\
\hline $\begin{array}{l}\text { Infant had other medical issues that } \\
\text { may have affected length of stay }\end{array}$ & $14(25)$ & $3(15)$ & $4(17)$ & 0.67 \\
\hline
\end{tabular}

Abbreviations: NAS, neonatal abstinence syndrome; SSRIs, selective serotonin reuptake inhibitors.

Note: Data are presented as $n(\%)$ or mean (standard deviation).

ancludes one infant who initially roomed-in with mother but was subsequently admitted to neonatal intensive care unit (NICU) for worsening symptoms of neonatal abstinence syndrome, and one infant who initially roomed-in but was subsequently apprehended by child and family services and moved to the NICU. All infants had a gestational age of at least 36 weeks.

${ }^{\mathrm{b}}$ Adapted with permission from McKnight et al. ${ }^{21}$

'Infants born from September 1, 2013, to September 30, 2014, following implementation of a rooming-in program at Kingston Health Sciences Centre in June 2013. All infants had a gestational age of at least 36 weeks.

${ }^{d}$ Infants born from May 1, 2012, to May 31, 2013, prior to implementation of rooming-in program at Kingston Health Sciences Centre. Excludes infants with gestational age $<36$ weeks and those who were apprehended by child and family services and/or who had a medical condition that required direct admission to the NICU. These infants would not have been eligible for the rooming-in program and had it existed at that time.

e Restricted to multiparous mothers. Excludes one missing value in 2013 to 2014 rooming-in group and three missing values in 2012 to 2013 nonrooming-in group.

fPrescribed (e.g., oxycodone, hydromorphone) and illicit.

${ }^{9}$ Clavicle fracture, congenital cystic adenomatoid malformation, head injury, hyperbilirubinemia, hypoglycemia, left ventricular hypertrophy, possible seizure, Rh isoimmunization skull fracture. 
Table 2 Comparison of need for morphine, breastfeeding rates, and hospital length of stay among opioid-exposed newborns prior to and following the implementation of a rooming-in program at Kingston Health Sciences Centre

\begin{tabular}{|c|c|c|c|c|c|c|}
\hline & $\begin{array}{l}2015-2019 \\
\text { rooming-in } \\
\text { group }^{\mathrm{a}} \\
(n=57)\end{array}$ & $\begin{array}{l}2013-2014 \\
\text { rooming-in } \\
\text { group b,c } \\
(n=20)\end{array}$ & $\begin{array}{l}2012-2013 \\
\text { nonrooming-in } \\
\text { group b,d } \\
(n=24)\end{array}$ & $\begin{array}{l}2015-2019 \\
\text { rooming-in vs. } \\
2012-2013 \\
\text { nonrooming-in }\end{array}$ & $\begin{array}{l}2015-2019 \\
\text { rooming-in vs. } \\
2013-2014 \\
\text { rooming-in }\end{array}$ & $\begin{array}{l}2013-2014 \\
\text { rooming-in vs. } \\
2012-2013 \\
\text { nonrooming-in }^{\mathrm{a}}\end{array}$ \\
\hline $\begin{array}{l}\text { Required } \\
\text { morphine, } n(\%)\end{array}$ & $2(3.5)$ & $3(15)$ & $20(83)$ & $<0.001$ & 0.11 & $<0.001$ \\
\hline $\begin{array}{l}\text { Breastfed during } \\
\text { hospital stay, } n(\%)\end{array}$ & $47(82)$ & $14(70)$ & $12(50)$ & 0.003 & 0.34 & 0.18 \\
\hline $\begin{array}{l}\text { Hospital length of } \\
\text { stay in d, } \\
\text { median (IQR) }\end{array}$ & $5.0(4.0-5.0)$ & $5.0(4.0-7.0)$ & $24.0(12.0-35.5)$ & $<0.001$ & 0.10 & $<0.001$ \\
\hline
\end{tabular}

Abbreviation: IQR, interquartile range.

${ }^{a}$ Includes one infant who initially roomed-in with mother but was subsequently admitted to neonatal intensive care unit (NICU) for worsening symptoms of neonatal abstinence syndrome, and one infant who initially roomed-in but was subsequently apprehended by child protective services and moved to the NICU. All infants had a gestational age of at least 36 weeks.

${ }^{\mathrm{b}}$ Adapted with permission from McKnight et al. ${ }^{21}$

'Infants born from September 1, 2013, to September 30, 2014, following implementation of the rooming-in program at Kingston Health Sciences Centre in June 2013. All infants had a gestational age of at least 36 weeks.

dInfants born from May 1, 2012, to May 31, 2013, prior to implementation of rooming-in program at Kingston Health Sciences Centre. Excludes infants with gestational age $<36$ weeks and those who were apprehended by child protectives services and/or who had a medical condition that required direct admission to the NICU. These infants would not have been eligible for the rooming-in program and had it existed at that time.

${ }^{\mathrm{e}}$ Exclusive or in combination with formula.

groups. No significant differences were observed. Of note, all three groups included mothers with OUD and/or chronic pain diagnoses. In 57 dyads in the 2015 to 2019 cohort, methadone was prescribed as OAT in 36 of the pregnancies (median daily dose $=70 \mathrm{mg}$; interquartile range (IQR) $=40.0-115.0$ ) and buprenorphine/naloxone was prescribed in 10 pregnancies (median daily buprenorphine dose $=12$ $\mathrm{mg}$; $\mathrm{IQR}=8.0-20.0$ ). In the remaining 11 pregnancies, various opioid agonists were used for maternal diagnoses other than OUD, primarily chronic pain. None of the 57 infants who roomed-in was readmitted to our hospital within 30 days of discharge.

As shown in - Table 2, two of the 57 infants who initially roomed-in (3.5\%) required morphine to treat their NAS. One was admitted to the NICU for this purpose; the second infant was apprehended by CFS after initially rooming-in with its mother and was transferred to the NICU, only after which signs of NAS worsened to the point where morphine was initiated. When compared with the 2012 to 2013 nonrooming-in cohort, a significantly lower proportion of the 2015 to 2019 cohort required morphine. Significant improvements in breastfeeding rates (82 vs. 50\%) and length of stay in hospital (5 vs. 24 days) were also observed. There were no significant differences in these outcomes when comparing the 2015 to 2019 cohort to the 2013 to 2014 pilot cohort.

\section{Discussion}

In 5 years since we reported on outcomes in the first cohort of opioid-dependent infants who roomed-in at our hospital, the benefits initially observed have been maintained or have increased. The proportion of infants requiring pharmacological treatment decreased from $15 \%$ in the first year to $3.5 \%$ over the subsequent 5-year period. While this proportion is lower than previous published reports of the effects of rooming-in, it is in keeping with the $6 \%$ of similar infants reported by Grossman et al, who also significantly lowered the average LOS through the use of a quality improvement methodology that replaced Finnegan scoring with an ESC approach that maximized nonpharmacological therapies. ${ }^{22}$ The median length of stay however was unchanged between the 2013 to 2014 and the 2015 to 2019 cohorts. The proportion of infants with any exposure to breastfeeding increased from 70 to $82 \%$ between these two groups. These findings are consistent with those of other authors who have reported the effects of rooming-in. ${ }^{15-19,25}$

Our subjective experience suggests some of this improvement may be due in part to an increasing confidence among the clinicians (A.I.N. and L.N.) involved in caring for these mother-infant dyads, further bolstered by emerging evidence reporting the benefits of an ESC approach. ${ }^{4,24,40}$ While we continued to use modified Finnegan scoring throughout the study period, we were more persistent with nonpharmacological treatments during the latter half, particularly because initiation of pharmacotherapy necessitated admission to the NICU and interruption of the benefits of roomingin that were becoming more evident. In July 2020, our hospital initiated the use of an ESC tool rather than Finnegan scoring, and now permits the initiation of pharmacotherapy without transfer to the NICU.

Forty-three of the 100 opioid-dependent infants delivered at our hospital during the study period were excluded from the study because they did not meet our criteria to room-in with their mothers. It is a sad irony that these are precisely the infants who might benefit the most from close contact with family members and the use of nonpharmacological treatments. 
Our objective was to examine whether the benefits observed in the first year of the rooming-in program ${ }^{21}$ were sustained over a longer observation period. Our study was limited by the small cohort size. Finally, the fact that 11 of the infants observed were born to women taking opioid medication for a chronic pain diagnosis and who did not have a primary diagnosis of OUD is a potential limitation. While this was also true of the NICU cohort from 2012 to 2013 described in McKnight et $\mathrm{al}^{21}$ it is likely that women diagnosed primarily with pain might be distinct from women diagnosed with and treated for OUD.

\section{Conclusion}

The data presented here add to accumulating evidence that rooming-in for near-term opioid-dependent newborns is an effective way of minimizing the incidence and severity of NAS while avoiding separation of the mother-infant dyad. This is in keeping with the conclusions reached by Wachman et al: infants at risk of NAS should be cared for outside of an intensive care unit where feasible; they should room-in with one or both parents; and they should be breastfed if there are no contraindications. ${ }^{29}$ Unfortunately, fully $43 \%$ of the infants delivered at our hospital who were identified as being at risk for NAS were unable to room-in, either because of medical comorbidities, child protection concerns, or both. Infants born to opioid-dependent women in our community appear to be at high risk of requiring an intensive care environment. Our experience has reinforced our belief that while rooming-in is the optimal means of caring for such infants where possible, a proportion will inevitably require intensive care, which currently necessitates separation from their mothers; it will fall to those seeking to introduce family-centered care to the NICU to mitigate this additional stress on this most vulnerable subset of an already vulnerable population, who are likely to benefit from the nonpharmacological therapies currently accessible only to those infants afforded the opportunity to room-in.

\section{Conflict of Interest}

A.I.N. reports personal fees from Knight Therapeutics, outside the submitted work. All the other authors report no conflict of interest.

\section{References}

1 Special Advisory Committee on the Epidemic of Opioid Overdoses. Opioid-related Harms in Canada. Ottawa: Public Health Agency of Canada March 2020. Accessed August 1, 2020 at: https://health-infobase.canada.ca/substance-related-harms/ opioids

2 Orpana HM, Lang JJ, Baxi M, et al. Tendances canadiennes en matière de mortalité liée aux opioïdes et d'invalidité découlant d'un trouble de consommation d'opioïdes, à la lumière de l'Étude sur la charge mondiale de morbidité (1990-2014). Health Promot Chronic Dis Prev Can 2018;38(06):234-243

3 Dawson E, Lew J, Mauer-Vakil D, Van Dijk A, Belanger P, Moore KM. A longitudinal analysis of temporal and spatial incidence of neonatal abstinence syndrome in Ontario: 2003-2016. J Opioid Manag 2019;15(03):205-212
4 MacMillan KDL. Neonatal abstinence syndrome: review of epidemiology, care models, and current understanding of outcomes. Clin Perinatol 2019;46(04):817-832

5 Stanford Children's Health. Neonatal Abstinence Syndrome. May 2020. Available at: https://www.stanfordchildrens.org/en/topic/default?id=neonatal-abstinence-syndrome-90-

P02387 "https://www.stanfordchildrens.org/en/topic/default? id=neonatal-abstinence-syndrome-90-P02387". Accessed August 1, 2020

6 Murphy-Oikonen J, Montelpare WJ, Southon S, Bertoldo L, Persichino $\mathrm{N}$. Identifying infants at risk for neonatal abstinence syndrome: a retrospective cohort comparison study of 3 screening approaches. J Perinat Neonatal Nurs 2010;24(04):366-372

7 Maguire DJ, Taylor S, Armstrong K, et al. Long-term outcomes of infants with neonatal abstinence syndrome. Neonatal Netw 2016; 35(05):277-286

8 Cairns PA. Drug misuse: conception into childhood. Curr Paediatrics 2001;11(06):475-479

9 Hunt RW, Tzioumi D, Collins E, Jeffery HE. Adverse neurodevelopmental outcome of infants exposed to opiate in-utero. Early Hum Dev 2008;84(01):29-35

10 Pritham UA, Paul JA, Hayes MJ. Opioid dependency in pregnancy and length of stay for neonatal abstinence syndrome. J Obstet Gynecol Neonatal Nurs 2012;41(02):180-190

11 Filteau J, Coo H, Dow K. Trends in incidence of neonatal abstinence syndrome in Canada and associated healthcare resource utilization. Drug Alcohol Depend 2018;185:313-321

12 United Nations Children's Fund \& World Health Organization. Protecting, promoting and supporting breastfeeding in facilities providing maternaity and newborn services: the revised BABYFRIENDLY HOSPITAL INITIATIVE. 2018. Accessed August 1, 2020 at: https://apps.who.int/iris/bitstream/handle/10665/272943/ 9789241513807-eng.pdf? sequence $=19$ \&isAllowed $=y$

13 Cleveland Clinic. Rooming-in: rest is healing. January 1, 2018. Accessed August 1, 2020 at: https://my.clevelandclinic.org/health/articles/15275-rooming-in-rest-is-healing

14 Davies GA, Newman A, Newton L, et al. Maternal satisfaction with rooming-in to reduce neonatal abstinence syndrome (poster). BJOG Int J Obstet Gynaecol 2015;122(S2):265-266

15 Abrahams RR, Kelly SA, Payne S, Thiessen PN, Mackintosh J, Janssen PA. Rooming-in compared with standard care for newborns of mothers using methadone or heroin. Can Fam Physician 2007;53(10):1722-1730

16 Saiki T, Lee S, Hannam S, Greenough A. Neonatal abstinence syndrome-postnatal ward versus neonatal unit management. Eur J Pediatr 2010;169(01):95-98

17 Hodgson ZG, Abrahams RR. A rooming-in program to mitigate the need to treat for opiate withdrawal in the newborn. J Obstet Gynaecol Can 2012;34(05):475-481

18 Hünseler C, Brückle M, Roth B, Kribs A. Neonatal opiate withdrawal and rooming-in: a retrospective analysis of a single center experience. Klin Padiatr 2013;225(05):247-251

19 Newman A, Davies GA, Dow K, et al. Rooming-in care for infants of opioid-dependent mothers: Implementation and evaluation at a tertiary care hospital. Can Fam Physician 2015;61(12): e555-e561

20 Holmes AV, Atwood EC, Whalen B, et al. Rooming-in to treat neonatal abstinence syndrome: improved family-centered care at lower cost. Pediatrics 2016;137(06):e20152929

21 McKnight S, Coo H, Davies G, et al. Rooming-in for infants at risk of neonatal abstinence syndrome. Am J Perinatol 2016;33(05): 495-501

22 Grossman MR, Berkwitt AK, Osborn RR, et al. An initiative to improve the quality of care of infants with neonatal abstinence syndrome. Pediatrics 2017;139(06):e20163360

23 Howard MB, Schiff DM, Penwill N, et al. Impact of parental presence at infants' bedside on neonatal abstinence syndrome. Hosp Pediatr 2017;7(02):63-69 
24 Wachman EM, Grossman M, Schiff DM, et al. Quality improvement initiative to improve inpatient outcomes for neonatal abstinence syndrome. J Perinatol 2018;38(08): 1114-1122

25 Lembeck AL, Tuttle D, Locke R, et al. Outcome differences in neonates exposed in-utero to opioids managed in the NICU versus the pediatric floor. J Addict Med 2019;13(01):75-78

26 Cree M, Jairath P, May O. A hospital-level intervention to improve outcomes of opioid exposed newborns. J Pediatr Nurs 2019; 48:77-81

27 MacMillan KDL, Rendon CP, Verma K, Riblet N, Washer DB, Volpe Holmes A. Association of rooming-in with outcomes for neonatal abstinence syndrome: a systematic review and meta-analysis. JAMA Pediatr 2018;172(04):345-351

28 Coyle MG, Brogly SB, Ahmed MS, Patrick SW, Jones HE. Neonatal abstinence syndrome. Nat Rev Dis Primers 2018;4(01):47

29 Wachman EM, Schiff DM, Silverstein M. Neonatal abstinence syndrome: advances in diagnosis and treatment. JAMA 2018; 319(13):1362-1374

30 MacVicar S, Kelly LE. Systematic mixed-study review of nonpharmacological management of neonatal abstinence syndrome. Birth 2019;46(03):428-438

31 Whalen BL, Holmes AV, Blythe S. Models of care for neonatal abstinence syndrome: What works? Semin Fetal Neonatal Med 2019;24(02):121-132

32 Grossman M, Berkwitt A. Neonatal abstinence syndrome. Semin Perinatol 2019;43(03):173-186
33 Ryan G, Dooley J, Gerber Finn L, Kelly L. Nonpharmacological management of neonatal abstinence syndrome: a review of the literature. J Matern Fetal Neonatal Med 2019;32(10):1735-1740

34 Statistics Canada 2016 Census Profile, Kingston, Ontario. Accessed May 24, 2020 at: https://www12.statcan.gc.ca/censusrecensement/2016/dp-pd/prof/details/page.cfm?Lang=E\&Geo1 $=$ CSD\&Code $1=3510010 \&$ Geo $2=$ PR\&Code $2=35 \&$ Search Text=Kingston $\&$ SearchType $=$ Begins $\&$ SearchPR=01\&B1=All\&GeoLevel=PR\&GeoCode=3510010\&TABID $=1 \&$ type $=0$

35 Queen's Printer for Ontario. 2014, Southeast Ontario Local Health Integration Network. Accessed May 24, 2020 at: http://www. southeastlhin.on.ca

36 Kingston Community Health Centres. 2020. Thrive. Accessed May 24, 2020 at: http://kchc.ca/weller-avenue/thrive

37 Hudak ML, Tan RCCommittee on Drugs Committee on fetus and newborn American Academy of Pediatrics. Neonatal drug withdrawal. Pediatrics 2012;129(02):e540-e560

38 Dow K, Ordean A, Murphy-Oikonen J, et al.Neonatal Abstinence Syndrome Work Group. Neonatal abstinence syndrome clinical practice guidelines for Ontario. J Popul Ther Clin Pharmacol 2012; 19(03):e488-e506

39 Fenton TR, Kim JH. A systematic review and meta-analysis to revise the Fenton growth chart for preterm infants. BMC Pediatr 2013;13:59

40 Grossman MR, Lipshaw MJ, Osborn RR, Berkwitt AK. A novel approach to assessing infants with neonatal abstinence syndrome. Hosp Pediatr 2018;8(01):1-6 